\title{
The Ontology of Biological Groups: Do Grasshoppers Form Assemblages, Communities, Guilds, Populations, or Something Else?
}

\author{
Jeffrey A. Lockwood \\ Department of Philosophy, University of Wyoming, Department 3392, 1000 E. University Avenue, Laramie, WY 82071, USA \\ Correspondence should be addressed to Jeffrey A. Lockwood, lockwood@uwyo.edu \\ Received 5 August 2010; Accepted 11 November 2010 \\ Academic Editor: Alexandre Latchininsky \\ Copyright (C) 2011 Jeffrey A. Lockwood. This is an open access article distributed under the Creative Commons Attribution \\ License, which permits unrestricted use, distribution, and reproduction in any medium, provided the original work is properly \\ cited. \\ Acridologists have used a variety of terms to describe groups of grasshoppers, including assemblage, community, guild, and \\ population. This terminological diversity has raised the question of whether one of these descriptors is the correct one. I take \\ the position that these terms pick out different features of the natural world such that there is no unconditionally or uniquely \\ correct term. By adopting the framework of constrained perspectivism—a form of philosophical pragmatism—it is argued that a \\ term is correct if it accurately reflects the conceptual framework of the investigator and effectively communicates this perspective \\ to others. Such an approach gives rise to terminological pluralism that avoids the problems of relativism (the subjectivist's view \\ that any term can be used) and absolutism (the objectivist's view that there is a single correct term). I describe the contexts in \\ which the most common terms are appropriate.
}

\section{Introduction: The Problem}

Acridologists have used various terms to describe the groups of grasshoppers that are the focus of their work. The terms most often used are assemblage, community, guild, and population. Using the Google Scholar [1] to analyze how frequently scientists have used these terms revealed that of 1,459 hits: "grasshopper assemblage" appeared 65 times (4\%), "grasshopper community" 413 times (28\%), "grasshopper guild" 1 time $(<1 \%)$, and "grasshopper population" 980 times $(67 \%)$.

One might respond to the assortment of terms by asserting that such variety does not imply a problem or confusion. In fact, this view was expressed by three reviewers of this paper. These scientists tacitly agreed that the ecological terms were well defined (we will see that this is demonstrably not the case in the discussion of "population" and to some extent with "community" and "guild") or at least there was no confusion among acridologists. But their explications revealed a conceptual morass with various contradictions.
The first reviewer maintained that "the only issue is the occasional sloppy individual who calls a grasshopper assemblage a community." For this scientist, there is a single, correct term for groups of grasshoppers, which is "assemblage" (for the moment, let us set aside the fact that the supposedly sloppy use of "community" occurs far more often than the putatively correct term of "assemblage" - and "population" is more commonly used than either of these). By this account, all right-thinking acridologists know that groups of grasshoppers are called "assemblages," so the case is closed.

In an ironic twist, the second reviewer contended that all the terms have "tight and accepted usages," such that there is simply no confusion among acridologists. For this scientist, there are four standard terms that are variously and correctly used to describe groups of grasshoppers. But both reviewers cannot be correct. Either the first acridologist is in error (not all groups are "assemblages") or the second reviewer is mistaken (terms other than "assemblage" are conceptual errors). 
The situation becomes no clearer with the assertion of the third reviewer that, "the choice of terms by researchers seems relatively uninformative/unimportant as some researchers may rather arbitrarily choose a term.” In other words, this scientist agreed with the first in that some researchers were sloppy, but s/he seemed quite uncommitted to the notion that all groups are properly called "assemblages." And this reviewer also contradicted the second in suggesting that the chosen term is uninformative. The resolution, according to the third reviewer, is that the word choice is unimportant: "what matters is the context of how those words are used in a journal article." This represents a wholly inefficient approach to terminology-rather like referring to locusts in a title or abstract, only to have the reader discover that the paper is about grasshoppers - and it presumes that scientists take the time to read entire articles. Oftentimes and justifiably, researchers use titles to find the literature on a particular kind of grouping (e.g., community), and if others use an arbitrary term (e.g., assemblage or population) as a label, then important work will be overlooked and irrelevant publications will be sought.

At this point, all we can safely assert is that at least some acridologists_-including apparently three highly qualified and experienced practitioners_-are collectively confused by the terminology applied to groups of grasshoppers. Based on my experience, many graduate students and junior scientists working in this field are also somewhat bewildered by which term should be used to describe a group of grasshoppers in a habitat. So, it would appear that the editors of this special issue of Psyche were on to something in identifying one of the topics of interest as "Grasshopper species in a habitat: a community or an assemblage?"

One solution is to simply presume that the correct term is that which is used by the majority of scientists. If so, then a group of grasshoppers should be called a population (not "community" or "assemblage", as proposed by the editors). However, this seems entirely too quick of a solution to the terminological problem. It is certainly possible that most workers are misusing or misunderstanding a term. Moreover, we cannot summarily conclude that all of the scientists describing grasshopper groups are necessarily referring to one and the same thing. To clearly frame the problem-along with possible solutions and their shortcomings - it is helpful to consider four possibilities.

1.1. The Terms for Grasshopper Groups Are Synonyms. The various terms might be synonyms, much as one might refer to "short-horned grasshoppers" in one paper and to "acridids" in another, or to "nymphs" in one place and "hoppers" in another. If so, the inconsistencies are not substantive at all. However, the problem with the different expressions for groups of grasshoppers seems more than a matter of alternative words for the same entity. Ecologists form different impressions from the various terms used by acridologists; a "population" picks out something in nature that is not the same thing as a "community" [2]. Hence, the possibility of substantive errors and misunderstandings is real.
1.2. The Terms for Grasshopper Groups Are Subjective Constructs. The various terms may simply reflect human artifice. The manner in which grasshoppers are grouped could be an entirely subjective matter, such that there is no basis to argue for one formulation over another. A nominalist (i.e., one who holds that beyond the reality of individual entities, all higher groupings are human inventions) might contend that while individual grasshoppers actually exist, any amalgamation of these individuals represents a cultural construct-a sort of potentially useful fiction [3]. As such, one could be a realist about single grasshoppers but an antirealist about groups of grasshoppers [4]. Taken to an extreme, one could just as defensibly combine grasshoppers based on the potential they have as fish bait, the third letter of their scientific name, or the color of their tibia as one might group them in terms of competitive interactions, behavioral tendencies, or taxonomic relations. But such a strong nominalist view strikes us as rather implausible. Certain groupings of grasshoppers seem to reflect nonarbitrary qualities of the organisms (e.g., those that eat only grasses) much more so others (e.g., those that happen to be airborne at a given moment).

\subsection{The Terms for Grasshopper Groups Are Objective Truths.} There could be an objective fact of the matter as to which term uniquely picks out a real thing in the world [5]. A realist might argue that groups of grasshoppers are actual, mindindependent entities and that these possess some unifying property that makes it correct to call them communities but not populations, for example. Perhaps groups of grasshoppers are like deer herds, wherein the individuals have interactions or relationships which form a distinct entity. However, a strong realist position seems difficult to defend. It is not unambiguously evident what relationship among the grasshoppers makes the collective into an actual, objectively existing whole. At least there does not appear to be a single candidate for such a relationship, as the interactions might be understood in various terms (e.g., mutualism with regard to predator swamping or competition in terms of food acquisition). And this leads us to the fourth and most viable possibility.

1.4. The Terms for Grasshopper Groups Are Interactional Perspectives. The terms used to describe groups of grasshoppers could reflect neither purely subjective nor objective criteria. There may be multiple, biologically compelling ways of identifying groups although it will also be the case that some approaches are absurd. For the pluralist $[6,7]$, there is more than one way of being right (contrary to the objective absolutist), but it is still possible to be wrong (contrary to the committed subjectivist). As such, the groupings of grasshoppers are interactional [8], being "made"-rather than subjectively created or objectively discovered-through the interests of the scientist interacting with the rich (but not unlimited) possibilities of the real world. That is to say, reality can be divided in many ways, but not just any way. Thus, the researcher has a particular perspective with respect to 
a line of inquiry and thereby picks out one of the biologically plausible ways to group grasshoppers.

Such an approach to understanding some biological groups has been advanced-at least implicitly-by ecologists. In his analysis of the concept of communities, Underwood [9] described the subjectivist and objectivist views. The former position is that "communities are simply a human invention...used to describe the collection of organisms that are found in the same place at the same time," and the latter view is that communities are "valid and necessary object[s] of study" which are held together through biological interactions. Underwood [9] observed that these two perspectives have been alternately in favor and that "the reality is probably somewhere in between" although he does not specify an intermediate view. However, his contention that no definition will satisfy all-or even mostecologists, opens the door to the possibility of a pluralistic approach.

\section{Analogous Cases and Their Implications for Grasshopper Groups}

2.1. Perspectival Approaches to Individual Entities. Is an axe a weapon or a tool? The group of implements to which an axe belongs does not seem to be objectively (or at least singularly) determinable. The right assignment of the axe depends on how it is used. In the hands of Lizzie Borden (who according to legend and the children's ditty "took an axe and gave her mother forty whacks"), the thing should be considered a weapon, but in the hands of Paul Bunyan (the mythic lumberjack), it is a tool. Nor is the correct term for the axe merely a philosophical puzzle-the consequences of being wrong could be serious. The problem of how to perceive an axe persists even when the instrument is not in the hands of others. That is, my own intentions or interests are critical to what category of things the axe belongs to when I reach for the instrument.

The "axe problem" reveals an important aspect of how we categorize objects. The subjective perspective of the individual engaging the objective entity is critical to our understanding. Scientific perspectivism $[10]$ is the view that the ontology (what is real) and metaphysics (the properties of real things/processes) are both constrained by the facts (e.g., the axe is a heavy, sharp object so it is nonsensical to use it as a pillow) and open to an array of possible interests (e.g., weapon, tool, doorstop, etc.). The pluralism that arises from this understanding underwrites a philosophy of ecology that is called constrained perspectivism [11].

Starting with the categorization of an axe creates an accessible starting point, but groups of entities (e.g., grasshoppers) are not necessarily single things. We might contend that an axe is not a single item but is composed of a handle and a head, but these parts seem to be so intimately related in terms of the function of the whole that treating an axe as a particular item is appropriate. In fact, that is the matter we are trying to resolve: are groups of grasshoppers real things (ontology) and what sorts of things are they (metaphysics)?
2.2. Perspectival Approaches to Collective Entities. Imagine that a person walks into a room containing old furniture. The individual wants to describe what he sees and wonders about the correct term to use for the group of chairs, tables, lamps, and whatnot. The challenge is whether there is a single, right way to convey to others what he has observedis there an objective descriptor? It seems not, as the most accurate term will depend on his interests and those of the persons with whom he will be communicating. If the man is a furniture dealer, he may tell his assistant that he has come across an "inventory of antiques." However, if he is a historian and recognizes that the furniture is a matched set from a single room of Louis XIV, the grouping might be termed a "17th century salon." But if the fellow is an artist, he might see the placement and spacing of the furniture as aesthetically pleasing and refer to the items as a "balanced arrangement of three-dimension forms." And finally, if the man is a millionaire, he might perceive the furniture as a "collection of status-enhancing objects." The point here is that there appears to be no uniquely right term for the assembled items. The interests of the observer and those with whom he is speaking are inextricably woven into choosing the right description.

This is not to say that there is no way to be wrong about a term for the furniture. In fact, there are at least two mistakes to be made. First, the man could simply use a term that does not pertain to groupings of furniture. For example, the millionaire could tell his interior decorator that he found a "squadron of furniture" or the antique dealer could tell his assistant to prepare the shop for a "herd of chairs and tables". Neither description is meaningful or appropriate for items of furniture-there is a category error in using such terms.

Second, the man could use a term that is uninformative or even misleading to the listener. If the artist tells his impoverished bohemian friend that he should go to see the "collection of status-enhancing objects," the other fellow would likely be confused — or at least not understand why he ought to be interested. Or if the historian submits a paper to the Journal of French History reporting that he came across a "balanced arrangement of three-dimensional forms," then he has failed to tell his colleagues what is important about his observation.

\subsection{Perspectival Approaches to Scientific Referents. Before} we consider the importance of terminology for groups of grasshoppers, it is useful to briefly consider two analogous cases in science and why the use of alternative terms mattered.

In physics, there has been considerable debate as to the nature of light $[12,13]$. Following Newton, most scientists accepted some version of the "corpuscular hypothesis" in which light was taken to be composed of particles. In the 18th century, Leonhard Euler advocated a wave theory of light (Newton also contended that "aetheric waves" played a role, although this was largely ignored). Both the particle and wave advocates were able to construct sound arguments and compelling experiments in defense of their views. Thomas Young's famous double-slit experiment set the stage for our 
contemporary understanding that light is both wave and particle-and how one perceives its nature depends on the choice of instrument or, in effect, one's interests. It matters a great deal in physics whether something is a wave or a particle, but at least with respect to light there is no objective fact of the matter.

In ecology, one's interests are critical to the interpretation of an organism's role in a habitat. Consider the case of Echium plantagineum in Australia [14]. For those with an interest in producing high-grade honey or ruminant livestock feed in drought stricken regions, the plant is a beneficial component of the ecosystem and warrants the common name "Salvation Jane". But for those who have an interest in restoring native habitats or producing quality forage on disturbed pastures, the plant deserves the moniker "Patterson's Curse". Whether this plant is a beneficial or pest species matters a great deal-and the right classification or term depends on one's interests.

So, is there a correct term for a group of grasshoppers? The American pragmatist William James [15] argued that:

the human mind is essentially partial. It can be efficient at all only by picking out what to attend to, and ignoring everything else,-by narrowing its point of view. Otherwise, what little strength it has is dispersed, and it loses its way altogether. Man always wants his curiosity gratified for a particular purpose.

This position would suggest that the acridologist must choose a perspective, that there is some particular interest being served by an investigation. Terminology is thus pragmatic (reflective of interests), perspectival (based on where one stands conceptually), and pluralistic (dependent on more than a single, correct, or objective viewpoint). So there is a right term to use for a given situation-whatever most accurately conveys the intentions of the researcher and communicates this point of view to fellow scientists.

\section{The Right Term for a Group of Grasshoppers: Conceptual Context}

If the pragmatic philosophy of constrained perspectivism with its pluralist solution is to be adopted by acridologists, there are three concepts to keep in mind as we consider the various terms that might be used to describe groups of grasshoppers.

3.1. Role of Objectivity. The acridologist faced with multiple terms for groups of grasshoppers might worry that the pluralist approach is a slippery slope. Can objectivity check the slide toward radical subjectivism? I will have more to say about this later, but for the present it is sufficient to maintain that objectivity can limit pluralism in two ways.

First, constrained perspectivists take it to be the case that there is a mind-independent world "out there", and reality constrains the ways in which we can productively frame our understanding [11]. In short, the world "pushes back" when we form beliefs that lead to actions which do not accord with external reality. If we think of a group of grasshoppers as a terrorist cell and launch a full-scale military attack to destroy them, the world pushes back through the economic costs, political repercussions, environmental damage, and social condemnation of our foolishness.

Second, objectivity is an important "regulative ideal" an unattainable goal which we can rationally adopt so as to orient our pursuits (not unlike global peace or economic justice). But our understanding is invariably domainspecific. As Reiners and Lockwood [11] maintained, "We can rise above individual bias, but we cannot ascend to a God's eye view such that truth is no longer relative to a particular conceptual system." So, we must be keenly aware of our chosen perspective and then aspire to unbiased understanding within this framework. One might even say that we should try to be as objective as possible about and within our subjective context.

3.2. Nature of Groups. In some biological settings, groups are readily observable. The group of cells comprising an organism is quite evident, and even some ecological groups are discernible (e.g., a herd of deer, a school of fish, a swarm of locusts). However, most groups of grasshoppers that are studied by ecologists are not visible. This is not a challenge particular to acridology. Indeed, Reiners and Lockwood [11] made the case that:

$[\mathrm{M}]$ any ecological entities are not perceived (i.e., seen by our eyes or instruments), but conceived. . ecology is particularly prone to ontological and metaphysical problems such that we are concerned with how to carve up the world into entities and processes that are often unobservable (has anyone actually seen species, speciation, communities, metabolism, ecosystems, or equilibrium?).

For the most part there are not directly observable properties of a group of grasshoppers that provide a kind of objective taxonomy. That said, we may be able to infer qualities of the collective via sampling (e.g., density and species composition). Furthermore, various instruments and measurements have been developed to discern the effects of the group (e.g., forage loss and nitrogen levels).

3.3. Practical Relevance. In the context of pragmatism, James [15] maintained that "There can be no difference anywhere that does not make a difference elsewhere." That is to say, a distinction between "population" and "community", for example, is vacuous if there is no actual consequence of calling a group by one or the other of these names. Perhaps this is why there seem to be few arguments about whether acridologists should refer to "nymphs" or "hoppers"; the distinction makes no difference in terms of our beliefs and actions. As will be evident in the following section, the terms which we apply to groups of grasshoppers may well make a difference with regard to orienting the research agenda of science, communicating our findings, and perhaps even developing sound government policies and taking effective management actions. These potential consequences should not be surprising in light of other cases in which how 
scientists have chosen terms and perspectives mattered (see Perspectival approaches to scientific referents).

3.4. Principled Relevance. Assuming that the reader is not entirely on board with the framework of pragmatism that is captured by constrained perspectivism [11], there is a principled reason why the choice of terms in science matters. That is, science is thought by many to be our closest approximation to the way the world actually is. Indeed, scientists generally favor the realist's view that we are justified in taking the referents of science to correspond with objective reality. If so, then the matter of what ecologists call groups of organisms is not an artificial controversy. Rather than making a philosophical mountain out of a scientific molehill, being clear and accurate in our language is vital to the practice of science. We would not countenance saying that 3.4 grasshoppers $/ \mathrm{m}^{2}$ was 4 grasshoppers $/ \mathrm{m}^{2}$ nor would we allow a colleague to refer to a katydid as a locust, so we should not be complacent about referring to a population as a community if, as I argue, we believe that these are essentially different entities.

\section{The Right Term for a Group of Grasshoppers: Plausible Options}

The predominant terms used to describe groups of grasshoppers are assemblage, population, community, and guild. Other terms for ecological groupings, such as association, inventory, and biocoenosis, can be subsumed under these more conventional descriptors.

4.1. Grasshopper Assemblage. An assemblage has the connotation of being a haphazard or accidental grouping of objects. This sense is reflected in the definitions used by ecologists. Allaby [2] provided the most fully elaborated account of the term:

a collection of plants and/or animals characteristically associated with a particular environment that can be used as an indicator of that environment (e.g., in geobotanical exploration). The term has a neutral connotation. Its use does not imply any specific relationship between the component organisms, whereas terms such as "community" imply interactions.

The idea that an assemblage is whatever organisms happen to be present was echoed in Lewis' [16] more concise definition: "A collection of co-occurring populations." Although Underwood [9] did not explicitly define an assemblage, he used the term to describe collections of organisms that do not appear to form integrated units but simply reflect a shared physiological tolerance for a particular environment. Such a notion is clearly consonant with those of Allaby [2] and Lewis [16]. Lincoln et al. [17] provided a definition within the context of paleontology: "a group of fossils occurring together in the same stratigraphic level (an assemblage zone)." Even this definition is consistent with the "same place, same time" notion used by ecologists. Other authors of ecological and environmental references omit "assemblage" entirely [18-20], so one might presume that the term is somewhat limited in its use. However, Google Scholar [1] produced 1,100 hits for "bird assemblage" and 12,600 hits for "fish assemblage", so the term is evidently common with regard to some organisms. Botanists use the term "association" for stable plant communities $[17,19]$ which are taken to have greater ecological coherence than assemblages of animals.

If acridologists accept that a "grasshopper assemblage" is just whatever species happen to coexist in some habitat, then the term seems peculiar in light of scientific investigations. The neutrality of "assemblage" suggests that the scientist had no particular theoretical interest in the group of insects with respect to ecology or evolution. This would lead one to wonder why the individual bothered to amass data about a set of objects without some hypothesis having structured the research. Perhaps the most plausible response to this pertains to those works that are not hypothesis driven but represent descriptive natural histories. Pfadt's Western Grasshoppers [21] is a fine example of this kind of conceptual neutrality. In addition to purely descriptive scientific works, there may be nonscientific reasons for knowing about the grasshoppers at a particular time and place. However, these other reasons are not neutral with respect to other human interests.

Pest managers may not be acting within any conceptual ecological framework in making decisions about grasshoppers. Along with a decision support system (e.g., [22]), simply knowing what species are present and at what densities may be all that is required for economically sound action. As such, a scientist who is emulating the perspective of a pest manager might well be justified in referring to a "grasshopper assemblage"; all of the individuals present (and thereby constituting a potential object of suppression) are being perceived as a group without regard to further ecological inquiry.

As with pest managers, environmental managers of public lands, private reserves, and other habitats that support grasshoppers may be acting from the basis of agency standards, legislative mandates, or advisory board policies. Likewise, conservation objectives are grounded in a set of values external to ecological theory although they may be informed by scientific concepts. Just as the pest manager's interest is economic, the environmental manager's concern may be social, legal, or moral.

In the context of environmental management, "assemblage" would seem to be appropriate although there is also some use of "inventory" (this term generated 119 hits in Google but none in Google Scholar). This latter term seems to conceptually align with the metaphorical perspective of biodiversity conservation insofar as managers attend to the protection of a biological stockpile or warehouse. "Grasshopper inventory" was used by Walter et al. [23] in the context of conservation biology, and the term appears on the websites of the Konza Prairie Educational Program [24] and the Medford Oregon office of the Bureau of Land Management [25]. However, conservation biologists seem to more often refer to grasshopper assemblages; for example, "Responses of grasshopper assemblages to long-term grazing management in a semi-arid African savanna" [26] and 
"Effects of fire disturbance on grasshopper (Orthoptera: Acrididae) assemblages of the Comanche National Grasslands, Colorado" [27].

4.2. Grasshopper Population. The most common term for a group of grasshoppers is "population". In this regard, two questions are pertinent: is it legitimate to refer to a group of multiple species as a population, and what is the ecological interest/perspective that differentiates a population from an assemblage?

Various references are inconsistent with regard to whether the definition of population applies to more than one species. Lewis [16] favored the single species notion of a population as "A collective group of individuals of the same species (or other taxa in which individuals exchange genetic information) occupying a particular space." Likewise, Allaby [2] defined a population as "a group of organisms all of the same species, which occupies a particular area," but he goes on to note that this term can also be used in a statistical context for "any group of like individuals" (which presumably could include more than one species). The dual possibility of single and multiple species was echoed by Lincoln et al. [17].

Explicit allowance that "population" can refer to a group composed of one or more species is found in Allaby's earlier reference in which he maintained that a population can be individuals within a species ("e.g., the human population of a particular country") or a larger taxonomic group ("e.g., the bird population of a particular area") [19]. This broader approach was endorsed by Martin and Hine [20], who defined a population as both, "A group of individuals of the same species within a community" and "The total number of individuals of a given species or other class of organisms in a defined area, e.g. the population of rodents in Britain." So, it appears that acridologists are not misusing "population" when referring to a group comprised of more than a single species.

The ecological perspective that is reflected in referring to a group as a population is evident in the definitions. Allaby [19] states that this term obtains when a group is "considered without regard to interrelationships among (the individuals)," and "when describing phenomena that affect the group as a whole (e.g., changes in numbers)." Hence, it is the dynamics of the group, its spatial distribution, or temporal changes, that motivate the investigation of a population. Indeed, many references include entries pertaining to these qualities, such as "population biology", "population density", "population dynamics", "population ecology", and "population growth" $[17-20,28]$. Thus, an acridologist seems to be justified in calling a group of grasshoppers a population if the purpose of the investigation is to understand the factors which explain the spatial patterns or (particularly) temporal dynamics of the organisms. As such, it seems quite appropriate to use this term in contexts such as: "A perspective of grasshopper population distribution in Saskatchewan and interrelationship with weather" [29] and "A simulation model for testing the dynamics of a grasshopper population" [30].
4.3. Grasshopper Community. Aside from "population", the most common term for a group in acridology is "grasshopper community". And once again, two questions are pertinent: is it legitimate to refer to a group comprised of only a single family as a community, and what is the ecological interest that differentiates a community from an assemblage or population?

Although few terms in ecology generate full agreement with regard to definitions, there appears to be considerable consensus as to what makes a group of organisms a community. In all of the references considered for this paper, the authors made clear that a community is comprised of different species $[2,16-20,28]$. However, there appears to be no indication that these species must include members of different higher taxa (i.e., multiple families, orders, classes, phyla, or kingdoms). Only Martin and Hine [20] refer to communities as including plants and animals, but they also note that "Larger communities can be divided into smaller communities," which could presumably include a single taxonomic family. In fact, Google Scholar [1] searches for "bird community" and "fish community" both generated more than 10,000 hits. As such the term "grasshopper community" seems entirely appropriate with regard to its scope of taxonomic inclusion. This leaves the question of what qualities make a group of grasshoppers a community.

There is also considerable agreement that for a group of organisms to constitute a community there must be interactions (e.g., trophic, mutualistic, and competitive relationships) among the individuals that provide structure $[2,17,20]$. Even definitions that do not make the relational aspect explicit are suggestive of such a criterion. Both Parker's [18] "distinctive combination of species" and Allaby's [19] "naturally occurring group of organisms that occupy a common environment" would seem to imply, if not require, that a relational factor unites the collective.

The matter of there being valid grasshopper communities would seem to be settled except for the confusion that arises with an allied term. Underwood [9] opens the door with his description of early marine ecologists who had to dredge or otherwise grab samples in a haphazard fashion because they were unable to see into the habitat. The term used to describe the group of collected organisms was "biocoenosis". This was evidently a nonnatural collection of species taken from a particular location at a given time. As such, one might suppose that this would have been an assemblage. However, the ecologists described these groups in terms of being equilibrial communities, so the interactions among the organisms served as the conceptual context. The result of this hybridization of assemblage and community was terminological confusion. While Parker [18], Lewis [16], and Lincoln et al. [17] equated "biocoenosis" with "community", Allaby [19] explicitly defined a coenosis as "A random assemblage of organisms that have common ecological requirements, as distinct from a Community." To make matters worse, Lincoln et al. [17] noted that biocoenosis is often used as an alternative term for "ecosystem", and Allaby [2] equated it with "biome". With regard to acridology, Google Scholar [1] revealed no citations with the term 
TABLE 1: Terminology used for groups of grasshoppers and the perspectives in which these descriptors are most appropriate.

\begin{tabular}{|c|c|}
\hline Term & Context \\
\hline Assemblage & $\begin{array}{l}\text { When there is primarily a nonecological interest in the economic or other values of the group, such as in pest management } \\
\text { or conservation }\end{array}$ \\
\hline Inventory & $\begin{array}{l}\text { When there is primarily a nonecological interest in the group as a component of biodiversity, most often for the purposes } \\
\text { of conservation }\end{array}$ \\
\hline Population & $\begin{array}{l}\text { When there is primarily an ecological interest in the spatiotemporal dynamics of the group and the factors that account for } \\
\text { these quantitative changes }\end{array}$ \\
\hline Community & $\begin{array}{l}\text { When there is primarily an ecological interest in the interactions within the group (e.g., mutualism and competition) and } \\
\text { how these structure membership }\end{array}$ \\
\hline Biocoenosis & $\begin{array}{l}\text { Perhaps equivalent to "community," but the ambiguity in use is such that the term is probably not a clear expression of a } \\
\text { particular perspective }\end{array}$ \\
\hline Guild & $\begin{array}{l}\text { When there is primarily an ecological interest in the role that the group plays in its use of a common resource, usually in a } \\
\text { similar fashion }\end{array}$ \\
\hline
\end{tabular}

"grasshopper biocoenosis," although there was one reference to "grasshopper coenosis".

Given the ambiguity and rarity of (bio)coenosis to describe groups of grasshoppers and the most common view that the term is equivalent to "community", it seems reasonable to suggest that the latter term be used. The appropriate context for the use of "grasshopper community" is when the scientist is interested in the ecological relationships among the individuals (e.g., competition for food or trophic interactions) and how these bind the collective into a coherent group. It should be noted that "grasshopper community" may include nongrasshopper species as communities are often named for the dominant, but not sole, taxon [17]. Examples of studies in which interactions are the perspective taken by the researcher include "Arid grassland grasshopper community structure: comparisons with neutral models" [31] and "The role of vertebrate and invertebrate predators in a grasshopper community" [32].

4.4. Grasshopper Guild. The term "guild" is not often used to describe a group of grasshoppers. However, it is worth considering what sorts of features this concept picks out and the contexts in which it would be appropriately used (versus assemblage, population, or community).

Although "guild" is not defined in several of the sources used in this analysis $[18,20,28]$, those that include the term agree on its meaning: a group of (perhaps closely related) species which use an ecological resource, usually in a common fashion $[16,17,19]$. Like a community, a guild includes multiple species. But the distinguishing feature of the group is more specific than in the case of a community, where any relationship could provide a conceptual unification. Because of their reliance on a common resource, members of a guild have a similar role in the community [17].

It is the scientist's interest in this ecological function (and the fact that such a function actually exists) that makes it appropriate to refer to the "forbivore guild of grasshoppers" or the "scavenger guild of grasshoppers". An apropos use of the term is exemplified by Owen-Smith and Dankerts [33]:

Grasshoppers in the Pyrgomorphidae, as well as certain of the Pamphagidae, Catantopinae and Tettigoniidae, feed primarily on forbs and small shrubs. Evidently nibbling by the grasshopper guild is more evenly spaced over the herbaceous layer than is grazing by ungulates.

"Guild" is presumably uncommon in the acridological literature because of the relatively narrow specificity of the research interest. The diverse feeding habits of grasshoppers means that they are collectively subsumed under herbivory (detritivorous and necrophagous behaviors notwithstanding), and to refer to the "herbivore guild" (or even the "insect herbivore guild") would entail many taxa other than Acrididae or Orthoptera. However, there would appear to be some cases in which grasshoppers can be reasonably understood to comprise a guild.

4.5. Terminological Perspectivism. The terms used for groups of grasshoppers should (and often do) reflect the interests of the scientist, such that others can reasonably infer the ecological or other perspective of a particular study. There may well be more terms for groups than I have analyzed here, and should these alternatives more effectively communicate the nature of an investigation they ought to be used. However, the descriptors in Table 1 represent the most common terms used by acridologists and ecologists and cover many, perhaps most, of the ways that we perceive grasshoppers in the field.

\section{Summary: The Pragmatist's View of the Right Term for a Group of Grasshoppers}

No investigation of a group of grasshoppers is motivated by all of the interests pertinent to acridology. For example, if one is attempting to understand the interactions among individuals within a given year, then it is not plausible to be also investigating the environmental factors associated with 
the numerical dynamics of the group over the course of a century. But neither is it defensible to contend that one or the other of these perspectives is better or somehow more reflective of actual groups of insects in the world. We might think of the ways of perceiving a group of grasshoppers as being ecological lenses. The features visible through the "community lens" are not evident via the "population lens". Giere [10] recognized the importance of understanding scientific inquiries as partial truths when he argued the following:

[T] his multiple rootedness need not lead to "anything goes" perspectival relativism, or an antinaturalist worship of common sense, experience, or language. It yields a kind of multi-perspectival realism anchored in the heterogeneity of "piecewise" complementary approaches common in biology and the study of complex systems.

At this point, one might reasonably wonder about the nature of truth for the advocates of constrained perspectivism. Is terminology merely a matter of linguistic convention or can we assert that a term is correct? The philosophy of pragmatism entails what has been called radical empiricism [34], an approach consonant with scientific inquiry. We know what is true via our testing of ideas through their application in the world. The pragmatists eschewed debates about ontology and metaphysics that were not based on biophysical evidence. Arguing about reality and its properties was a fruitless endeavor unless there were actual consequences of being right (or wrong). This view gave rise to Richard Rorty's analysis that truth is the compliment we pay to ideas that work [11]. What then does it mean for an idea to "work"?

According to the pragmatists, an idea worked if it served as the basis for an action resulting in an outcome that satisfied genuine (not superficial or merely expedient) needs and desires. In short, an idea was true if it led to behaviors that fulfilled our interests as human beings. It is this concept that allows one to assert that a particular term for a group of grasshoppers is the right one.

The test of whether "grasshopper population" or "grasshopper community" is a true description of a group of these insects is rather straightforward. Does adopting a particular perspective and using the associated term allow us to act in the world in ways that accord with our interests (both with regard to understanding the organisms and being understood by our colleagues)? The term "grasshopper population" is the right choice if this conceptual framework facilitates our investigation of a feature of the group (e.g., the rate of change in the density of the insects by the application of an appropriate model) and conveys to others the nature of our inquiry (e.g., our investigation concerns spatiotemporal dynamics rather than interactions structuring the group or other possible interests).

In this pragmatic context, I would propose that one of the reasons why pest management of rangeland grasshoppers is often conducted with nominal regard to beneficial and innocuous acridid species is the conceptual lumping that follows from referring to "grasshopper population outbreaks". In effect, treatment programs target all of the grasshopper species which are amalgamated into a single group of pestiferous insects. And such homogenization can have highly deleterious consequences, such as the inadvertent suppression of high densities of beneficial species [35]. One has to wonder whether such mistakes might be avoided if we focused on ecological relations and referred to treatments of "grasshopper communities". Such a terminological shift might entail our paying significantly greater attention to the more ecologically complex functions of these insects. In this context, treating a "grasshopper assemblage" might be politically expedient but fail to convey the environmental concerns that attend pest management interventions.

As scientists, we want to pick out "natural kinds" in the world-those groups that represent objective, mindindependent collections of individuals $[36,37]$. And there is reason to believe, for example, that "all of the grasshoppers that eat forbs" in a given habitat reflects an actual ecological group of individuals much more so than "all grasshoppers that were named by Samuel Hubbard Scudder". In the end, however, the pragmatist recognizes that we do not have direct access to the way the world really is; we cannot know if our perspective uniquely or wholly corresponds with objective reality. What we can know is whether reality exists in such a way that our acting as if a group was real leads to actions that yield results consistent with human needs and wants. The right term for a group of grasshoppers is one that picks out and communicates one of a large number of "useful kinds" [11] - and it is my hope that this paper has made some practical contribution to our understanding of the natural world and one another.

\section{References}

[1] Google Scholar, "Online search engine," April 2010, http:// scholar.google.com/scholar?q=google\&rls=com.microsoft:enus\&oe $=U T F-8 \&$ startIndex $=\&$ startPage $=1 \& u m=1 \& i e=U T F-8$ $\& s a=N \& h l=e n \& t a b=w s$.

[2] M. Allaby, Oxford Dictionary of Ecology, Oxford University Press, New York, NY, USA, 2nd edition, 1998.

[3] N. Goodman, "Nominalisms," in The Philosophy of W. V. Quine, L. E. Hahn and P. A. Schilpp, Eds., pp. 159-161, Open Court, La Salle, Ill, USA, 1986.

[4] J. Leplin, "Introduction," in Scientific Realism, J. Leplin, Ed., pp. 1-7, University of California Press, Los Angeles, Calif, USA, 1984.

[5] A. Fine, "The natural ontological attitude," in Scientific Realism, J. Leplin, Ed., pp. 83-107, University of California Press, Los Angeles, Calif, USA, 1984.

[6] R. J. Bernstein, "Pragmatism, pluralism, and the healing of wounds," in Pragmatism: A Reader, L. Menard, Ed., pp. 382401, Vintage Press, New York, NY, USA, 1997.

[7] S. D. Mitchell and M. R. Dietrich, "Integration without unification: an argument for pluralism in the biological sciences," The American Naturalist, vol. 168, pp. S73-S79, 2006.

[8] G. Lakoff and M. Johnson, Metaphors We Live By, University of Chicago Press, Chicago, Ill, USA, 1980.

[9] A. J. Underwood, "Community," in Encyclopedia of Ecology, S. E. Jorgensen, Ed., pp. 689-694, Elsevier, Amsterdam, The Netherlands, 2008. 
[10] R. N. Giere, Scientific Perspectivism, University of Chicago Press, Chicago, Ill, USA, 2006.

[11] W. A. Reiners and J. A. Lockwood, Philosophical Foundations for the Practices of Ecology, Cambridge University Press, New York, NY, USA, 2010.

[12] A. R. Hall and M. B. Hall, A Brief History of Science, Signet, New York, NY, USA, 1964.

[13] A. Wolf, A History of Science, Technology, and Philosophy in the 18th Century, Harper and Brothers, New York, NY, USA, 1961.

[14] W.T. Parsons and E. G. Cuthbertson, Noxious Weeds of Australia, CSIRO Publishing, Collingwood, Australia, 2nd edition, 2001.

[15] W. James, The Will to Believe, Human Immortality, and Other Essays on Popular Philosophy, Dover, New York, NY, USA, 1956.

[16] W. H. Lewis, Ecology Field Glossary: A Naturalist's Vocabulary, Greenwood Press, Westport, Conn, USA, 1997.

[17] R. Lincoln, G. Boxschall, and P. Clark, A Dictionary of Ecology, Evolution and Systematics, Cambridge University Press, New York, NY, USA, 2nd edition, 1998.

[18] S. P. Parker, Encyclopedia of Environmental Science, McGrawHill, New York, NY, USA, 2nd edition, 1980.

[19] M. Allaby, Dictionary of the Environment, New York University Press, New York, NY, USA, 3rd edition, 1989.

[20] E. Martin and R. S. Hine, Eds., Oxford Dictionary of Biology, Oxford University Press, New York, NY, USA, 4th edition, 2000.

[21] R. E. Pfadt, Western Grasshoppers, Wyoming Agricultural Experiment Station Bulletin 912, University of Wyoming, Laramie, Wyo, USA, 3rd edition, 2002.

[22] L. K. Branting, J. D. Hastings, and J. A. Lockwood, "Integrating cases and models for prediction in biological systems," Artificial Intelligence Applications, vol. 11, no. 1, pp. 29-48, 1997.

[23] T. Walter, M. Hunziker, B. Peter, and P. Ward, “Threatened grasshopper species profit from ecological compensation areas," Grassland Science in Europe, vol. 9, pp. 234-236, 2004.

[24] Konza Prairie Educational Program, May 2010, http://keep.konza.ksu.edu/.

[25] Medford Oregon office of the Bureau of Land Management, May 2010, http://www.fs.fed.us/r6/sfpnw/issssp/documents/ inventories/inv-rpt-iior-chas-med-surveys-2008-09-25.pdf.

[26] S. Gebeyehu and M. J. Samways, "Responses of grasshopper assemblages to long-term grazing management in a semi-arid African savanna," Agriculture, Ecosystems \& Environment, vol. 95, no. 2-3, pp. 613-622, 2003.

[27] L. Nadeau, P. E. Cushing, and B. C. Kondratieff, "Effects of fire disturbance on grasshopper (Orthoptera: Acrididae) assemblages of the Comanche National Grasslands, Colorado," Journal of the Kansas Entomological Society, vol. 79, no. 1, pp. $2-12,2006$.

[28] S. E. Jorgensen, Ed., Encyclopedia of Ecology, vol. 1, Elsevier, Amsterdam, The Netherlands, 2008.

[29] S. H. Gage and M. K. Mukerii, "A perspective of grasshopper population distribution in Saskatchewan and interrelationship with weather," Environmental Entomology, vol. 6, pp. 469-479, 1977.

[30] G. Gyllenberg, "A simulation model for testing the dynamics of a grasshopper population," Ecology, vol. 55, pp. 645-650, 1974.

[31] A. Joern and L. R. Lawlor, "Arid grassland grasshopper community structure: comparisons with neutral models," Ecology, vol. 61, pp. 591-597, 1980.
[32] G. E. Belovsky and J. B. Slade, "The role of vertebrate and invertebrate predators in a grasshopper community," Oikos, vol. 68, no. 2, pp. 193-201, 1993.

[33] N. Owen-Smith and J. E. Dankwerts, "Herbivory," in Vegetation of South Africa, R. M. Cowling, D. M. Richardson, and S. M. Pierce, Eds., pp. 397-420, Cambridge University Press, New York, NY, USA, 1997.

[34] S. Haack and R. Lane, Eds., Pragmatism, Old and New: Selected Writings, Prometheus Books, Amherst, NY, USA, 2006.

[35] J. A. Lockwood, "Management of orthopteran pests: a conservation perspective," Journal of Insect Conservation, vol. 2, no. 3-4, pp. 253-261, 1998.

[36] D. H. Mellor, "Natural kinds," British Journal for the Philosophy of Science, vol. 28, pp. 299-331, 1977.

[37] B. Ellis, Scientific Essentialism, Cambridge Studies in Philosophy, Cambridge University Press, Cambridge, UK, 2001. 

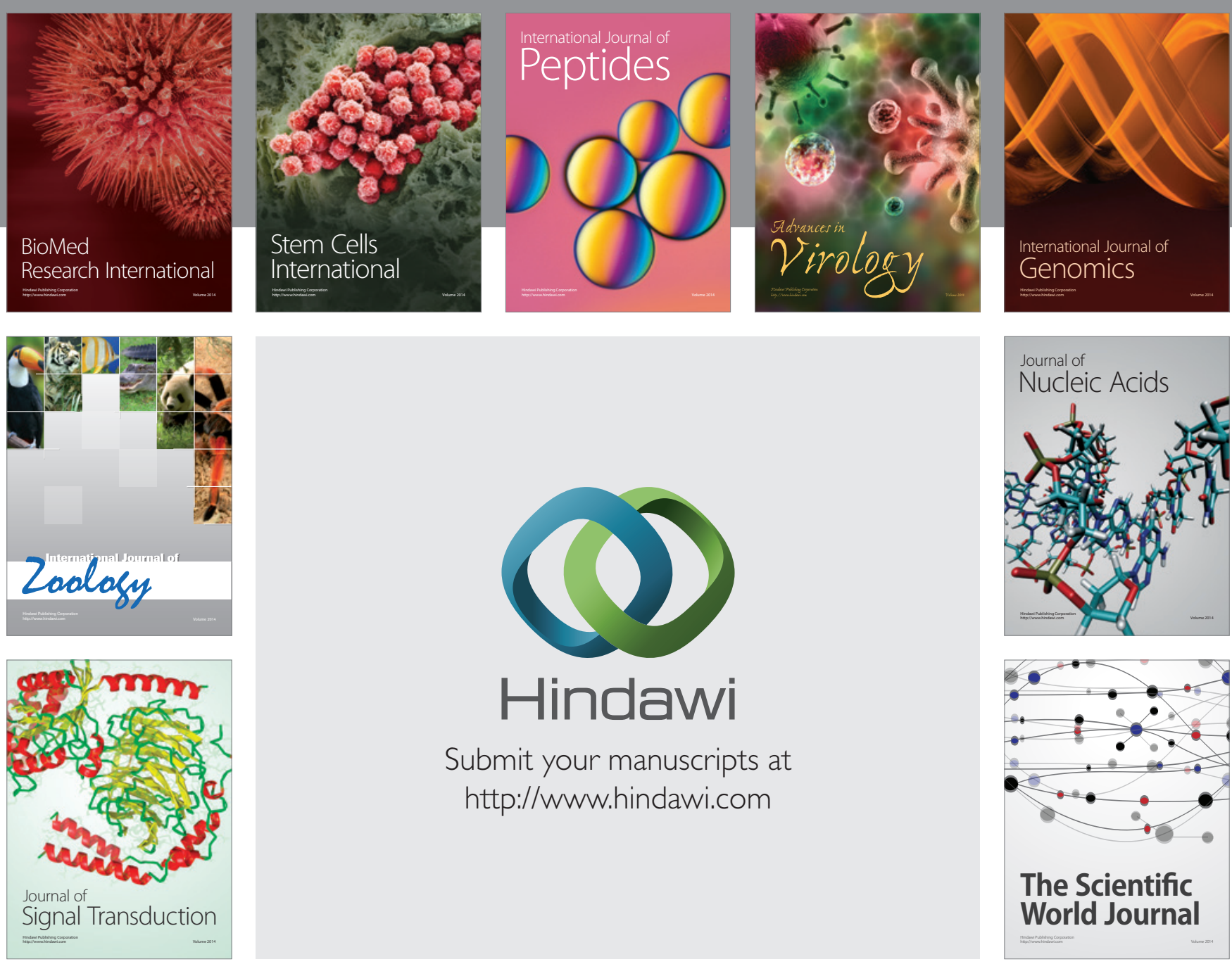

Submit your manuscripts at

http://www.hindawi.com
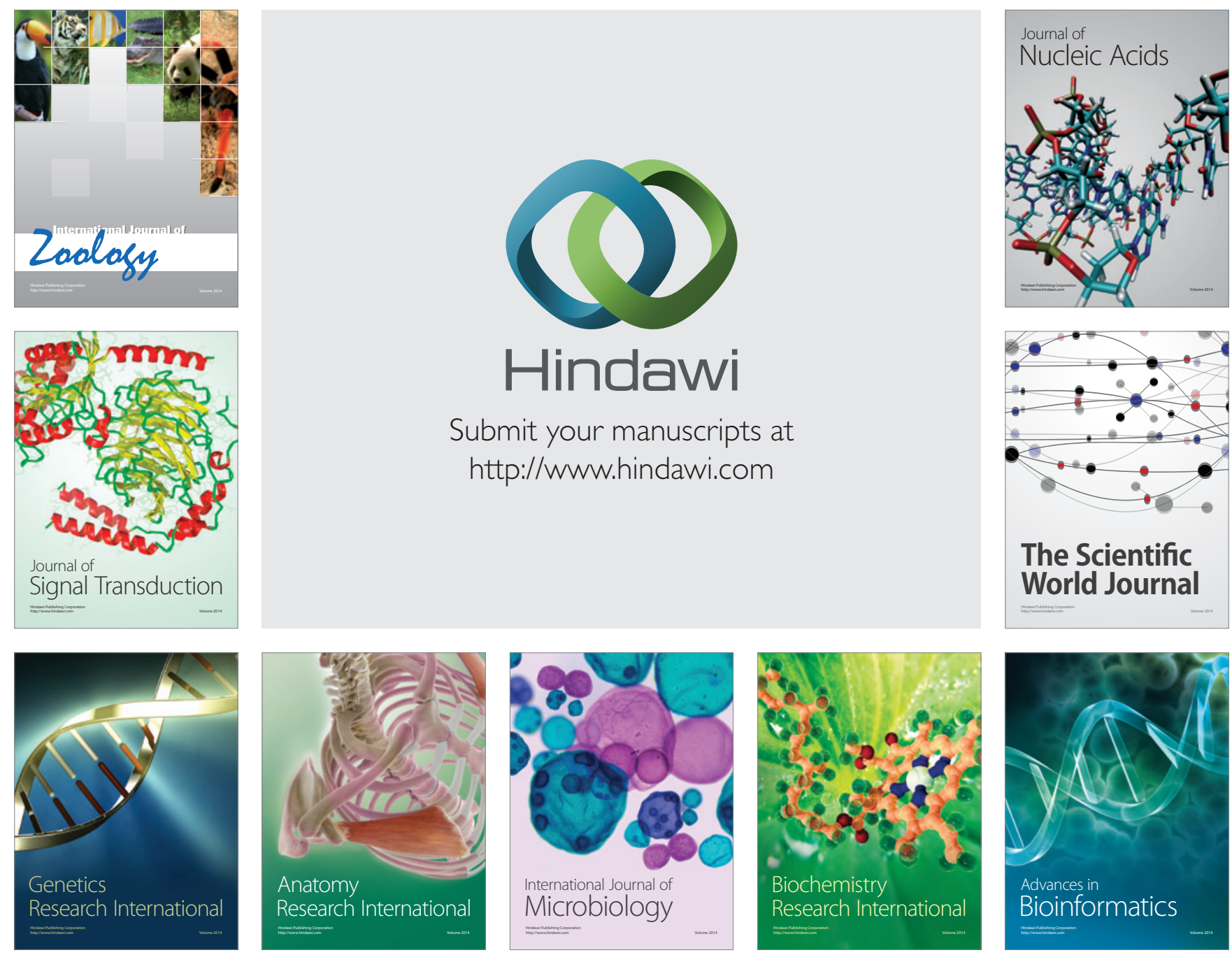

The Scientific World Journal
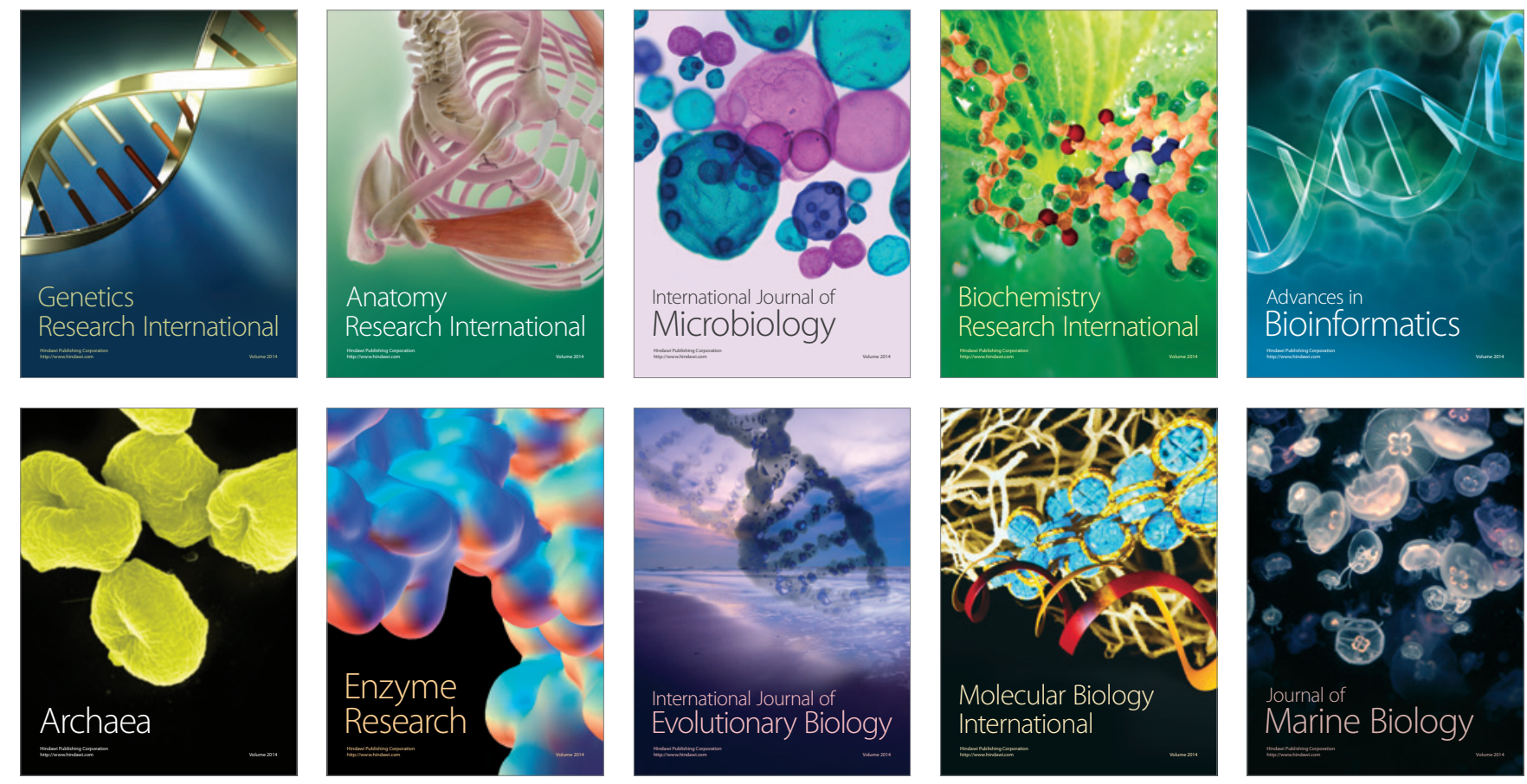